\title{
Evaluation of Students Performance using Fuzzy Set Theory in Online Learning of Islamic Finance Course
}

\author{
https://doi.org/10.3991/ijim.v15i07.20191 \\ Nashirah Abu Bakar ${ }^{(凶)}$ \\ Universiti Utara Malaysia, Kedah, Malaysia \\ nashirah@uum.edu.my \\ Sofian Rosbi \\ Universiti Malaysia Perlis, Perlis, Malaysia \\ Azizi Abu Bakar \\ Universiti Utara Malaysia, Kedah, Malaysia
}

\begin{abstract}
The objective of this study is to evaluate student performance using fuzzy set theory in Islamic Finance online course. This study focuses on selecting best individual among 30 students that registered for Islamic Bank Management course. The variables that involved in this study are online quiz marks, online assignment marks and online self-learning time. The outcome of the fuzzy set analysis was compared with final examination data. The methodology of this study involving converting real data to fuzzy set, intersection calculation, decision analysis using maximizing approach. Result of fuzzy set shows the best individual score is 0.9 . This student selected as best candidate for student performance in online learning with considering three variables namely online quizzes, online assignment and online self-learning hour. The comparison with final examination marks shows a good agreement with fuzzy set theory that concluded best individual from fuzzy set theory exhibits highest performance during final examination. The main finding of this study can help educators to predict the best performer in online learning class. In the same time, finding of this study can act as guideline to advise students in achieving their desired grade for online learning course.
\end{abstract}

Keywords-Fuzzy Set Theory; Student Performance; Online Learning; Islamic Finance

\section{Introduction}

Fuzzy logic was introduced in 1965 by Lotfi Zadeh. He has introduced the idea of fuzzy truth values and the associated idea of a fuzzy logic based upon these fuzzy truth values [1,2]. The function of fuzzy logic is to handle the concept of partial truth, where the truth value may range between completely true and completely false. Fuzzy logic can be applied to function representation and function implementation and the results may have useful applications to logic design, pattern recognition, fuzzy logic 
and related areas [3]. Fuzzy logic deals with the problems that have fuzziness or vagueness. In fuzzy set theory based on fuzzy logic a particular object has a degree of membership in a given set that may be anywhere in the range of 0 (completely not in the set) to 1 (completely in the set) $[4,5]$. Besides that, fuzzy logic is a new way to program computers and appliances to mimic the imprecise way humans make decisions [6-8].

Fuzzy set theory allows the elements of set to have varying degrees of membership, from a non-membership grade of 0 to a full membership of 100 per cent or grade 1. This smooth gradation of values is what makes fuzzy logic match well with the vagueness and uncertainty typical of many real-world problems [9-13]. However, study that focus fuzzy logic method implemented in the area of education is still lack of researches. Therefore, the objective of this study is to evaluate student performance using fuzzy set theory in Islamic Finance subject. Nowadays, the use of digital technologies in the most different areas and contexts become increasing intertwined with social life [14-19]. This study chose the subject Islamic Bank Management that are use Massive Open Online Learning (MOOC) method. MOOC is open online learning course platform that provided variety of courses. Students need to register via website and get more information regarding the courses that they register. MOOC online learning become a good platform in providing online teaching and learning lesson in higher education of Malaysia [20]. The objective of online learning is to provide a user-friendly environment of teaching and learning. Besides that, online learning platform provided a low cost, flexible schedule and can communicate with many students worldwide.

\section{$2 \quad$ Literature Review}

Fuzzy logic method was applied in various research areas. Although fuzzy logic is being extensively used in electronics and mathematical sciences, it has found little application in the social sciences, especially on education areas. Therefore, fuzzy logic approach found as a new innovation method in education fields. Study that focuses on the applied science fields suggested that fuzzy logic method is very useful method for automated health monitoring strategies [21] and this method can improve the effectiveness of computation [22]. In the others study found that fuzzy logic is capable of handling uncertainties and improving decision-making processes even with insufficient information [23].

Several studies have been found in education areas such the implementation of Intelligent Tutoring Systems in teaching and learning process [24], used of fuzzy logic method in measuring the performance of students [25] and used fuzzy logic simulation in examine either private higher education institution has the choice to adopt proactive or reactive strategy [26]. In recent decades there is a widespread interest used in the education system. With the continuous development of the internet, online learning was introduced in order to support the development of technology apply in education system. Malaysia was established Massive Open Online Courses (MOOCs) platform for online teaching and learning. MOOCs offered core modules and students 
from other public universities can participate in those courses through MOOCs online learning platform [27]. Online learning offers its learners access to education materials at their own pace and time as well as lowering the average educational learning cost [28] and the achievement of online learning can be improved by providing instruction in a manner consistent with each student's learning style [29].

\section{Research Methodology}

The objective of this research is to evaluate the best student performance using fuzzy set theory. Fuzzy sets theory proposes to deal with unclear boundaries, representing vague concepts and working with linguistic variables. In this sense, fuzzy sets emerged as an alternative way to deal with uncertainties. Fuzzy set is a mathematical set with the property that an object can be a member of the set, not a member of the set, or any of a continuum of states of being a partial member of the set. Fuzzy set applied to education to test the variables that contributes to success condition in final examination for course in Islamic Finance course. Simple functions are used to build membership functions. Because this study is defining fuzzy concepts, using more complex functions does not add more precision. Fuzzy set is a mathematical model of vague qualitative or quantitative data, frequently generated by means of the natural language. The model is based on the generalization of the classical concepts of set and its characteristic function. With the implementation of fuzzy set in the education evaluation, it will help educators to assess students in more reliable and robust method.

Fuzzy set theory is an extension of classical set theory where elements have degree of membership. Fuzzy logic uses the whole interval between zero (false) and one (true) to describe human reasoning. A fuzzy set is any set that allow its members to have different degree of membership, called membership function with interval $[0,1]$. A membership function for a fuzzy set $\mathrm{A}$ on the universe of discourse $\mathrm{X}$ is defined as $\mu_{A}: \mathrm{X} \rightarrow[0,1]$, where each element of $\mathrm{X}$ is mapped to a value between 0 and 1 . This value, called membership value or degree of membership, quantifies the grade of membership of the element in X to the fuzzy set A.

Membership functions allow us to graphically represent a fuzzy set. The $\mathrm{x}$ axis represents the universe of discourse, whereas the y axis represents the degrees of membership in the [0,1] interval. A fuzzy set is a pair $(U, m)$ with $U$ and $m$ is membership function. The membership function is represented by $m: U \rightarrow[0,1]$. The reference set represented by using $U$ for universe of discourse. The value of $m(x)$ is considered as the grade of membership for variable $x \in U$. The function $m=\mu_{A}$ is set as membership function for fuzzy set $A=(U, m)$. 


\section{$4 \quad$ Result and Discussions}

The objective of this study is to evaluate the best candidate among learners of online course. This study selected 30 students that enrolled in Islamic Bank Management course. The inputs variables are online quiz marks, online assignment marks and online self-learning hours. The benchmark variable is final examination marks.

The sample of student data is taken from study period of 15 week in one semester. The students are tested using two informative assessment which are online quizzes and online assignments. There are three quizzes were performed and two assignments that carried out by students. The assignment is divided to individual assignment and group assignments. In completing the study, the researchers develop qualitative measurement of self-dependence using self-online learning hours as indicator. Next, the final examination is performed by each student in assessing the understanding the course content by the end of semester of study period.

In developing a reliable and robust assessment method for student in Islamic Finance course, the independent variable needs to be converted to fuzzy membership value using fuzzy set. This study implemented fuzzy set to categorized the performance of student in final examination. The characteristics of students are difficult to analysis because the categorization of student performance is difficult to have clear boundaries between level of achievement among students. Therefore, this study implemented fuzzy set analysis to convert the input variables to fuzzy value.

Next, this study converted three input variables into fuzzy set. The first fuzzy set conversion is for online quiz marks using Equation (1).

$$
\mu_{A}(x)= \begin{cases}0 & ; 0 \leq x \leq 4 \\ \frac{x}{10} & ; 5 \leq x \leq 10\end{cases}
$$

Next, the second input namely online assignment marks using Equation (2). In this membership function, the value of online quiz from 0 to 5 is set as zero. Then, value that larger than 5 is using trapezium function.

$$
\mu_{B}(x)= \begin{cases}0 & ; 0 \leq x \leq 5 \\ \frac{x}{10} & ; 6 \leq x \leq 10\end{cases}
$$

Then, the third input namely online self-learning hours using Equation (3). In this membership function, the value of online self-learning hours from 0 to 6 is set as zero. Then, value that larger than 6 is using trapezium function.

$$
\mu_{C}(x)= \begin{cases}0 & ; 0 \leq x \leq 6 \\ \frac{x}{10} & ; 7 \leq x \leq 10\end{cases}
$$

Next, this study performed intersection operation of three types of fuzzy sets from three variables namely online quiz marks, online assignment marks and online student learning hours. The intersection operation was performed using Equation (4). 


$$
\mu_{M}(x)=\mu_{A \cap B \cap C}(x)=\min \left(\mu_{A}(x), \mu_{B}(x), \mu_{C}(x)\right), x \in U
$$

Next, this study performed maximization operation to evaluate best candidate among students using Equation (5).

$$
\begin{aligned}
X_{\max } & =\max \left(\mu_{M}(x)\right)=\max \left(\mu_{A \cap B \cap C}(x)\right) \\
& =\max \left(\min \left(\mu_{A}(x), \mu_{B}(x), \mu_{C}(x)\right)\right), x \in U
\end{aligned}
$$

In Equation (5), this study performed union operation for fuzzy set for universe matrix. The function of union after the intersection is to search for best candidate that involved with online assessments namely online quiz, online assignment and online self-learning hours. The Equation (5) performed involving intersection and union operation to calculate the best potential candidate in online course of Islamic Finance.

Next, this study performed union operation of fuzzy set to calculate best candidate for overall performance in online course of Islamic finance. From Table 1, the maximum value of intersection value is 0.9 for student with identification number 8 .

Then, this study comparing with examination marks to prove the finding in fuzzy set theory. The best performance of online learning is student number 8 with fuzzy value 0.9 . The final examination marks for student number 8 is 97 percentages. Therefore, the evaluation using fuzzy set is valid and reliable because the finding of fuzzy set is similar to outcome of final examination marks. The operation of fuzzy set including the setting of input variables is valid in determining student performance in online course of Islamic finance.

Table 1. Intersection operation using Fuzzy set theory

\begin{tabular}{|c|c|c|c|c|c|}
\hline $\begin{array}{c}\text { Student } \\
\text { Number }\end{array}$ & $\begin{array}{c}\text { Online Quiz } \\
\text { Marks }\end{array}$ & $\begin{array}{c}\text { Online } \\
\text { Assignment } \\
\text { Marks }\end{array}$ & $\begin{array}{c}\text { Online } \\
\text { Self-Learning } \\
\text { Hours }\end{array}$ & $\begin{array}{c}\text { Intersection } \\
\text { Value }\end{array}$ & $\begin{array}{c}\text { Final } \\
\text { Examination } \\
\text { Marks }\end{array}$ \\
\hline 1 & 0 & 0 & 0 & 0 & 50 \\
\hline 2 & 0 & 0 & 0 & 0 & 40 \\
\hline 3 & 0.6 & 0.7 & 0 & 0 & 63 \\
\hline 4 & 0.8 & 1.0 & 0.8 & 0.8 & 83 \\
\hline 5 & 0 & 0 & 0 & 0 & 43 \\
\hline 6 & 0 & 0 & 0 & 0 & 40 \\
\hline 7 & 0 & 0 & 0 & 0 & 40 \\
\hline 8 & 0.9 & 1.0 & 1.0 & 0.9 & 97 \\
\hline 9 & 0.7 & 0.8 & 0.7 & 0.7 & 73 \\
\hline 10 & 0 & 0 & 0 & 0 & 40 \\
\hline 11 & 0 & 0 & 0 & 0 & 47 \\
\hline 12 & 0.7 & 0.8 & 0.7 & 0.7 & 73 \\
\hline 13 & 0 & 0 & 0 & 0 & 47 \\
\hline 14 & 0 & 0 & 0 & 0 & 37 \\
\hline 15 & 0 & 0 & 0 & 0 & 33 \\
\hline 16 & 0.5 & 0.6 & 0 & 0 & 57 \\
\hline 17 & 0.8 & 0.7 & 0.7 & 0.7 & 73 \\
\hline 18 & 0 & 0 & 0 & 0 & 40 \\
\hline
\end{tabular}




\begin{tabular}{|l|c|c|c|c|c|}
\hline 19 & 0.6 & 0.8 & 0.7 & 0.6 & 70 \\
\hline 20 & 0.6 & 0.7 & 0.7 & 0.6 & 67 \\
\hline 21 & 0 & 0 & 0 & 0 & 40 \\
\hline 22 & 0.8 & 0.9 & 0.8 & 0.8 & 80 \\
\hline 23 & 0.7 & 0.8 & 0 & 0 & 70 \\
\hline 24 & 0.6 & 0.7 & 0 & 0 & 63 \\
\hline 25 & 0.5 & 0.7 & 0.7 & 0.5 & 63 \\
\hline 26 & 0.5 & 0.6 & 0 & 0 & 53 \\
\hline 27 & 0 & 0 & 0 & 0 & 40 \\
\hline 28 & 0 & 0 & 0 & 0 & 50 \\
\hline 29 & 0.7 & 0.8 & 0.7 & 0.7 & 73 \\
\hline 30 & 0.9 & 0.8 & 0.9 & 0.8 & 87 \\
\hline
\end{tabular}

\section{Conclusion}

The main objective of this study is to examine student performance in online learning course using fuzzy logic approach. The online course that selected in this study is Islamic Bank Management. The sample number of this study is 30 students that participate in online course. This study implemented fuzzy set theory using three input variables namely online quiz marks, online assignment marks and online self-learning hours. This study implemented union and intersection method for fuzzy set theory. Then, maximum value of intersection was calculated. Result shows student with fuzzy value 0.9 considered the best performance candidate for online learning class. Then evaluation with final examination marks indicates the agreement with fuzzy set theory analysis. This is proved that the fuzzy set theory is reliable and accurate in examine student performance for online learning courses.

The novelty of this study is it will help educators in predicting student performance for online class. The problem with online class is less face-to-face interaction, therefore the prediction and advising student performance is quite difficult to manage by educators. With the implementation of fuzzy set analysis, it will help educators to predict and advise students about amount of marks that need to attaint to increase their performance during final examination of online learning.

Further research can be extended to analysis another qualitative factor that contributes to success of student in their study. The suggestion of qualitative variables is motivation level, financial status and family support. This study can be carry out using survey instrument a research tool. The finding will help to compliment the fuzzy analysis. In the same time, this study can be carry out to more number of sample and involving more courses in online learning especially in Islamic finance education.

\section{Acknowledgement}

This research was supported by University Teaching and Learning Centre (UTLC) of Universiti Utara Malaysia (UUM) under Scholarship of Teaching and Learning Research Grant (SoTL). SO Code: 14148. 


\section{$7 \quad$ References}

[1] Zadeh, L.A. (1975). Fuzzy Logic and Approximate Reasoning. Synthese, 30, 407-428. https://doi.org/10.1007/bf00485052

[2] Yager, R. (1983). Presupposition in Binary and Fuzzy Logics. Kybernetes, 12(2), 135-139. https://doi.org/10.1108/eb005649

[3] Lee, E. and Chou, T. (1995). Fuzzy Threshold Functions and Applications. Kybernetes, 24(7), 99-122. https://doi.org/10.1108/03684929510095711

[4] Tsoukalas, L.H. and Uhrig, R.E. (1997). Fuzzy and Neural Approches in Engineering. John Wiley, NY.

[5] Kumar, V. and Joshi, R.R. (2005). Hybrid Controller Based Intelligent Speed Control of Induction Motor. Journal of Theoretical and Applied Information Technology, 71-75.

[6] Ray, K. and Chakraborty, A. (2011). A Fuzzy Version of Default Logic. International Journal of Intelligent Computing and Cybernetics, 4(1), 5-24.

[7] Metaxiotis, K., Psarras, J. and Samouilidis, E. (2003). Integrating Fuzzy Logic into Decision Suppport Systems: Current Research and Future Prospects. Information Management \& Computer Security, 11(2), 53-59. https://doi.org/10.1108/09685220310468592

[8] Lee, E. (1996). Intelligent Factories Using Fuzzy Expert Systems. Kybernetes, 25(3), 5155. https://doi.org/10.1108/03684929610116428

[9] Zadeh, L.A. (1965). Fuzzy sets. Information and Control, 8(3), 338-53.

[10] Beheshti, H. and Lollar, J. (2008). Fuzzy Logic and Performance Evaluation: Discussion and Application. International Journal of Productivity and Performance Management, 57(3), 237-246. https://doi.org/10.1108/17410400810857248

[11] Bannatyne, R. (1994). Development of Fuzzy Logic in Embedded Control. Sensor Review, 14(3), 11-14. https://doi.org/10.1108/eum0000000004241

[12] Stotts, L. and Kleiner, B. (1995). New Developments in Fuzzy Logic Computers. Industrial Management \& Data Systems, 95(4), 22-27. https://doi.org/10.1108/02635579510086 $\underline{706 \mathrm{a}}$

[13] Sobrino, A. (2013). Fuzzy Logic and Education: Teaching the Basics of Fuzzy Logic through an Example (by Way of Cycling). Education Sciences, 3(2), 75-97. https://doi. org/10.3390/educsci3020075

[14] Albina Hashimova, Valeriy Prasolov, Vyacheslav Burlakov and Larisa Semenova (2020). Flexible and Contextual Cloud Applications in Mobile Learning. International Journal of Interactive Mobile Technologies, 14(21), 51-63. https://doi.org/10.3991/ijim.v14i21.18469

[15] Douglas Rossi Ramos (2020). An Analysis of Subjectivation Processes Mediated by New Digital Technologies, International Journal of Emerging Technologies in Learning, 15(24), 15- 25. https://doi.org/10.3991/ijet.v15i24.19315

[16] Eko Aprianto, Oikurema Purwati, Syafi'ul Anam (2020). Multimedia-Assisted Learning in a Flipped Classroom: A Case Study of Autonomous Learning on EFL University Students, International Journal of Emerging Technologies in Learning, 15(24), 114-127. https://doi. org/10.3991/ijet.v15i24.14017

[17] Galina Volkovitckaia, Yuliya Tikhonova, Olga Kolosova (2020). Educational Experience in the Mobile Learning Environment: Consumer Behaviour Perspective, International Journal of Interactive Mobile Technologies, 14(21), 92-106. https://doi.org/10.3991/ijim. v14i21.18441

[18] Korlan Zhampeissova, Irina Kosareva, Uliana Borisova, (2020). Collaborative Mobile Learning with Smartphones in Higher Education, International Journal of Interactive Mobile Technologies, 14(21), 4-18. https://doi.org/10.3991/ijim.v14i21.18461 
[19] Paola Cabrera-Solano (2020). The Use of Digital Portfolios to Enhance English as a Foreign Language Speaking Skills in Higher Education, International Journal of Emerging Technologies in Learning, 15(24), 159-175. https://doi.org/10.3991/ijet.v15i24.15103

[20] Abu Bakar, N., Rosbi, S. (2019). Framework of Outcome-Based-Education (OBE) for Massive Open Online Courses (MOOCs) in Islamic Finance Education. International Journal of Advanced Engineering Research and Science, 6(10), 247-253. https://doi.org/ $10.22161 /$ ijaers.610.38

[21] Demirci, S., Hajiyev, C. and Schwenke, A. (2008). Fuzzy Logic-based Automated Engine Health Monitoring for Commercial Aircraft. Aircraft Engineering and Aerospace Technology, 80(5), 516-525. https://doi.org/10.1108/00022660810899883

[22] Vimal, K. and Vinodh, S. (2013). Application of Artificial Neural Network for Fuzzy Logic Based Leanness Assessment. Journal of Manufacturing Technology Management, 24(2), 274-292. https://doi.org/10.1108/17410381311292340

[23] Singh, M. and Soni, S. (2017). A Comprehensive Review of Fuzzy-based Clustering Techniques in Wireless Sensor Networks. Sensor Review, 37(3), 289-304. https://doi.org/ 10.1108/sr-11-2016-0254

[24] Machadoa, M.A.S., Moreira, T.D.R.G., Gomes, L.F.A.M., Caldeirad, A.M. and Santose, D.J. (2016). A Fuzzy Logic Application in Virtual Education. Procedia Computer Science, 91, 9-26.

[25] Semerci, C. (2004). The Influence of Fuzzy Logic Theory on Students' Achievement. The Turkish Online Journal of Educational Technology, 3(2), 56-61.

[26] Bourini, I.F. and Al-Bourini, F.A. (2017). Fuzzy Logic Approach to Simulate the Role of Academic Performance and Competition on Strategic Intention within Jordanian Higher Education Institutions", International Journal of Business and Society, 18(3), 567-584.

[27] Abu Bakar, N., Rosbi, S. and Abu Bakar, A. (2020). Robust Estimation of Student Performance in Massive Open Online Course using Fuzzy Logic Approach. International Journal of Engineering Trends and Technology (IJETT) - Editor's Issues, 143-152. https://doi. org/10.14445/22315381/cati2p223

[28] Ahmad Fesol, S.F., Salam, S. and Shaarani, A.S. (2017). An Evaluation of Students' Perception on MOOC Instructional Design Elements. Journal of Applied Environmental and Biological Sciences, 7(10), 173-179.

[29] Zapalska A. and Brozik, D. (2006). Learning Styles and Online Education. Campus-Wide Information Systems, 23(5), 325-335. https://doi.org/10.1108/10650740610714080

\section{Authors}

Nashirah Abu Bakar is a senior lecturer in Islamic Business School, Universiti Utara Malaysia. Her main research interest is Islamic Corporate Finance and management. Dr. Nashirah already published 58 articles in reputable international journals. Dr. Nashirah serves as reviewers for eight international journals.

Sofian Rosbi is a senior lecturer in Faculty of Applied and Human Sciences, Universiti Malaysia Perlis. His main research interest are structural equation modelling and optimization. He published 50 journal articles in reputable international journals.

Azizi Abu Bakar is an Associate Professor in Islamic Business School, Universiti Utara Malaysia. He is an active researcher in Islamic Business Study.

Article submitted 2020-12-01. Resubmitted 2021-02-08. Final acceptance 2021-02-08. Final version published as submitted by the authors. 